\title{
Prognostic value of FDG PET/CT in head and neck squamous cell carcinomas
}

\author{
This article was published in the following Dove Press journal: \\ OncoTargets and Therapy \\ 26 August 2015 \\ Number of times this article has been viewed
}

\author{
D Dequanter ${ }^{1,2}$ \\ M Shahla ${ }^{2}$ \\ C Aubert ${ }^{2}$ \\ Y Deniz ${ }^{2}$ \\ $P$ Lothaire $^{2}$ \\ 'Department of Oncology, Laboratory \\ of Experimental Radiotherapy, KU \\ Leuven, Leuven, Belgium; ${ }^{2} \mathrm{Head}$ and \\ Neck Department, Hôpital André \\ Vésale, $\mathrm{CHU}$ de Charleroi, Montigny \\ le Tilleul, Belgium
}

\begin{abstract}
Introduction: The purpose of this study was to evaluate the use of ${ }^{18} \mathrm{~F}$-fluorodeoxyglucose positron emission tomography/computed tomography $\left({ }^{18} \mathrm{~F}\right.$-FDG PET/CT $)$ to identify the presence of cervical lymph nodes metastases and extracapsular spread with histologic correlations in head and neck squamous cell carcinoma.
\end{abstract}

Methods: The medical records of 54 patients who underwent ${ }^{18} \mathrm{~F}-\mathrm{FDG}$ PET/CT for head and neck squamous cell carcinoma before surgery were reviewed. Receiver operating characteristic (ROC) analysis was performed to differentiate patients with cervical lymph node metastasis from those without lymph node metastasis. The same statistical analysis was done to differentiate cervical lymph nodes with extracapsular spread from those without extracapsular spread.

Results: Metastatic disease was diagnosed histologically in 49\% (26 of 54) of the patients. Extracapsular spread was present in ten of the 54 patients (19\%). When ROC curve analysis and maximum standardized uptake $\left(\mathrm{SUV}_{\max }\right)$ values were used to detect cervical lymph node metastasis, the area under the ROC curve was 0.96 and the optimal cutoff value for $\mathrm{SUV}_{\max }$ was 4.05 based on ROC curve analysis. The sensitivity and specificity of $\mathrm{SUV}_{\max }$ for the detection of cervical lymph node metastasis using this cutoff point were $92 \%$ and $88 \%$, respectively. When ROC curve analysis and $\mathrm{SUV}_{\text {max }}$ values were used in order to detect extracapsular spread, the area under the ROC curve was 0.86, and the optimal cutoff value for $\mathrm{SUV}_{\text {max }}$ was 4.15 based on ROC curve analysis. Using this cutoff value, the sensitivity and specificity of $\mathrm{SUV}_{\max }$ for the detection of extracapsular spread were $83 \%$ and $88 \%$, respectively.

Conclusion: In our study, a median ${ }^{18} \mathrm{~F}$-FDG PET/CT SUV ${ }_{\max }$ cutoff value of 4.15 was found to be related with cervical lymph node metastasis and extracapsular spread in patients with head and neck cancer.

Keywords: maximum standardized uptake value, PET/CT, head and neck cancer, lymph node metastases, extracapsular spread

\section{Introduction}

Many variables have been implicated in the prognosis of patients with head and neck cancer, but the presence of cervical lymph node metastasis, eventually associated with extracapsular spread, remains the most significant prognostic factor in terms of recurrence of cancer and survival of these patients. The presence of lymph node metastasis and, certainly, the presence of extracapsular spread reduce the 5-year survival rate by about $50 \%{ }^{1}$

Nowadays, positron emission tomography/computed tomography (PET/CT) using ${ }^{18} \mathrm{~F}$-fluorodeoxyglucose (FDG) is being increasingly carried out for the staging and localization of metastatic disease in patients with head and neck cancer. It has been reported to be superior to conventional imaging for the evaluation of patients with head and neck malignancies and to have a sensitivity of $77 \%-96 \%$ and a specificity of $82 \%-100 \%$ for the detection of cervical lymph node metastases from head and
Maandal, 6, 1652 Alsemberg, Belgium

Email didier.dequanter@pandora.be submit your manuscript $\mid$ www.dovepress.com

Dovepress

http://dx.doi.org/10.2147/OTT.S85479 
neck cancers. ${ }^{1,2}$ Indeed, the sensitivity of CT for diagnosis of cervical lymph node metastasis is about $81 \%$ and its specificity about $72 \%$, whereas the sensitivity and specificity of magnetic resonance imaging (MRI) range from 57\% to $77 \%$ and $57 \%$ to $72 \%$, respectively. ${ }^{3}$ The sensitivity and specificity of ultrasound in detecting cervical node metastasis were $81.4 \%$ and $64.2 \%$, respectively. ${ }^{4}$

The purpose of this study was to assess the value of ${ }^{18} \mathrm{~F}$-FDG PET/CT for determining the presence of cervical lymph nodes metastases and extracapsular spread in head and neck squamous cell carcinoma (HNSCC) and to identify its histologic correlates.

\section{Methods}

In this retrospective study, the medical charts of patients who were treated initially by surgery and who underwent FDG PET/CT before surgery were retrieved and reviewed. Hospital approval was obtained for this study. All the patients had histologically proven head and neck cancer and no radiological evidence of distant metastasis at the time of presentation. Patients with non-squamous-cell carcinoma, an unresectable tumor, distant metastasis, a history of prior head and neck cancer, and those who had previously undergone neck surgery or chemoradiotherapy were excluded.

The diagnostic evaluations at presentation included a complete physical examination, panendoscopy, CT and/or an MRI scan of the head and neck, and FDG PET/CT. All the patients underwent neck dissection at the time of primary surgery, unilaterally in 32 cases and bilaterally in 22 cases.

The FDG PET/CT images that determine regional lymph node and extracapsular spread status were reassessed. Pathologic lymph node metastases were recorded using the neck-level system of the imaging-based nodal classification. In each patient, the largest lymph node (based on maximum axial diameter) at the cervical level was used to determine the lymph node diameter. Maximal axial diameter was defined as the greatest dimension observed for all the lymph nodes on axial CT images, and measured using a mouse-controlled cursor. Patients were staged according to the 2002 American Joint Committee on Cancer (AJCC) staging system.

All the patients fasted for at least 6 hours before the PET/CT study. ${ }^{18} \mathrm{~F}-\mathrm{FDG}$ was injected intravenously (370-555 MBq) and scanning began 60 minutes later. No patients had a blood glucose level exceeding $130 \mathrm{mg} / \mathrm{dL}$ before ${ }^{18} \mathrm{~F}$-FDG injection, and no intravenous contrast agent was administered.

If ${ }^{18} \mathrm{~F}$-FDG uptake was perceptible in a certain lymph node, the case was deemed positive for metastasis, and conversely, if no ${ }^{18} \mathrm{~F}-\mathrm{FDG}$ uptake was observed in the region, the case was regarded as free of cervical lymph node metastasis. For semiquantitative analysis, ${ }^{18} \mathrm{~F}-\mathrm{FDG}$ maximum standardized uptake ( $\mathrm{SUV}_{\text {max }}$ ) values were measured by visually placing regions of interest around cervical lymph nodes with perceptible ${ }^{18} \mathrm{~F}$-FDG uptake. If multiple nodes showed perceptible uptake, the node with the highest $\mathrm{SUV}_{\text {max }}$ value was selected. All PET/CT results were compared with postoperative pathology results.

Receiver operating characteristic (ROC) analysis was performed to differentiate patients with cervical lymph node metastasis from those without lymph node metastasis. The same statistical analysis was done to differentiate cervical lymph nodes with extracapsular spread from those without extracapsular spread.

\section{Results}

Patient characteristics are given in Table 1. In the first group of patients with lymph node metastasis with extracapsular spread, the median age was 51 years. In the second group of patients with cervical lymph node metastasis with extracapsular spread, the median age was 59 years. The median age was 54 years in the group of patients with no cervical lymph node metastasis. In our study, most of the patients were men. Concerning the primary site localization, ${ }^{18} \mathrm{~F}-\mathrm{FDG} \mathrm{PET} / \mathrm{CT}$ showed that the primary site was mostly the larynx in the first group of patients. In patients with cervical lymph node metastasis without extracapsular spread, ${ }^{18} \mathrm{~F}-\mathrm{FDG}$ PET/CT showed that the primary tumor site was mostly the pharynx. ${ }^{18} \mathrm{~F}$-FDG PET/CT located the tumor equally in the buccal area and at the larynx in the last group of patients (Table 2).

Pathological stages T2 and T4 were identified in 10\% and $90 \%$ of the patients in the first group. In the second group of patients, most of the tumors were at stage T4. About $71 \%$ of the patients in the last group presented a lesion at stage T4 (Table 3).

The tumor was well or moderately differentiated in most of the cases. The mean tumor volume was $58 \pm 24 \mathrm{~mm}$ (range: 29-66; 95\% confidence interval).

Table I Patient characteristics

\begin{tabular}{llll}
\hline Parameter & $\begin{array}{l}\text { pN+ with } \\
\text { ECS (n=10) }\end{array}$ & $\begin{array}{l}\text { pN+ without } \\
\text { ECS (n=16) }\end{array}$ & $\begin{array}{l}\text { pN- } \\
(\mathbf{n}=\mathbf{2 8})\end{array}$ \\
\hline Median age (years) & $5 \mathrm{I}$ & 59 & 54 \\
Sex & & & \\
$\quad$ Male (\%) & 78 & 75 & 62 \\
$\quad$ Female (\%) & 22 & 25 & 38 \\
\hline
\end{tabular}

Abbreviations: $\mathrm{ECS}$, extracapsular spread; $\mathrm{pN}+$, patients with lymph node positive metastasis; $\mathrm{pN}-$, patients without lymph node metastasis. 
Table 2 Tumor localization

\begin{tabular}{llll}
\hline Parameter & $\begin{array}{l}\mathrm{pN}+\text { with ECS } \\
(\mathbf{n}=1 \mathbf{0})(\%)\end{array}$ & $\begin{array}{l}\mathrm{pN}+\text { without } \\
\mathrm{ECS}(\mathbf{n = 1 6 )}(\%)\end{array}$ & $\begin{array}{l}\mathrm{pN}- \\
(\mathbf{n}=\mathbf{2 8})(\%)\end{array}$ \\
\hline Site & & & \\
Buccal area & 20 & 37 & 39 \\
Larynx & 50 & 20 & 39 \\
Pharynx & 30 & 43 & 22 \\
\hline
\end{tabular}

Abbreviations: $\mathrm{ECS}$, extracapsular spread; $\mathrm{pN}+$, patients with lymph node positive metastasis; $\mathrm{p} N-$, patients without lymph node metastasis.

A total of 54 patients underwent cervical dissection, and 304 measures of cervical levels (I-V) were included in the analysis undertaken to identify the relationship between ${ }^{18}$ F-FDG PET/CT and histological findings. Metastatic disease was diagnosed histologically in 26 (49\%) of the 54 patients. Extracapsular spread was present in 10 of the 54 patients $(19 \%)$. The median nodal $\mathrm{SUV}_{\max }$ was $3.34 \pm 3.07$ (range, 1.0-20.4; 95\% confidence interval) in patients with lymph node metastasis without extracapsular spread. In patients with lymph node metastasis and extracapsular spread, the median nodal $\mathrm{SUV}_{\text {max }}$ was $4.16 \pm 2.45$ (range, 1.25-18.4; 95\% confidence interval).

When ROC curve analysis and $\mathrm{SUV}_{\max }$ values were used to detect cervical lymph node metastasis, the area under the ROC curve was 0.96 and the optimal cutoff value for $\mathrm{SUV}_{\max }$ was 4.05 based on ROC curve analysis. The sensitivity and specificity of $\mathrm{SUV}_{\max }$ for the detection of cervical lymph node metastasis using this cutoff point were $92 \%$ and $88 \%$, respectively (Figure 1).

When ROC curve analysis and $\mathrm{SUV}_{\max }$ values were used in order to detect extracapsular spread, the area under the ROC curve was 0.86 , and the optimal cutoff value for $\mathrm{SUV}_{\text {max }}$ was 4.15 based on ROC curve analysis. Using this cutoff value, the sensitivity and specificity of $\mathrm{SUV}_{\text {max }}$ for the detection of extracapsular spread were $83 \%$ and $88 \%$, respectively (Figure 2).

\section{Discussion}

Nodal staging is critically important for the adequate treatment of HNSCCs because the presence of cervical lymph

Table 3 Pathologic staging

\begin{tabular}{ccll}
\hline Parameter & $\begin{array}{l}\mathrm{pN}+\text { with ECS } \\
(\mathbf{n = 1 0 )}(\%)\end{array}$ & $\begin{array}{l}\mathrm{pN}+\text { without } \\
\mathrm{ECS}(\mathbf{n = 1 6 )}(\%)\end{array}$ & $\begin{array}{l}\mathrm{pN}- \\
(\mathbf{n}=\mathbf{2 8})(\%)\end{array}$ \\
\hline Pathologic & T category & & \\
T2 & 10 & 25 & 18 \\
T3 & 0 & 19 & 11 \\
T4 & 90 & 56 & 71 \\
\hline
\end{tabular}

Abbreviations: ECS, extracapsular spread; $\mathrm{pN}+$, patients with lymph node positive metastasis; $\mathrm{pN}$-, patients without lymph node metastasis.

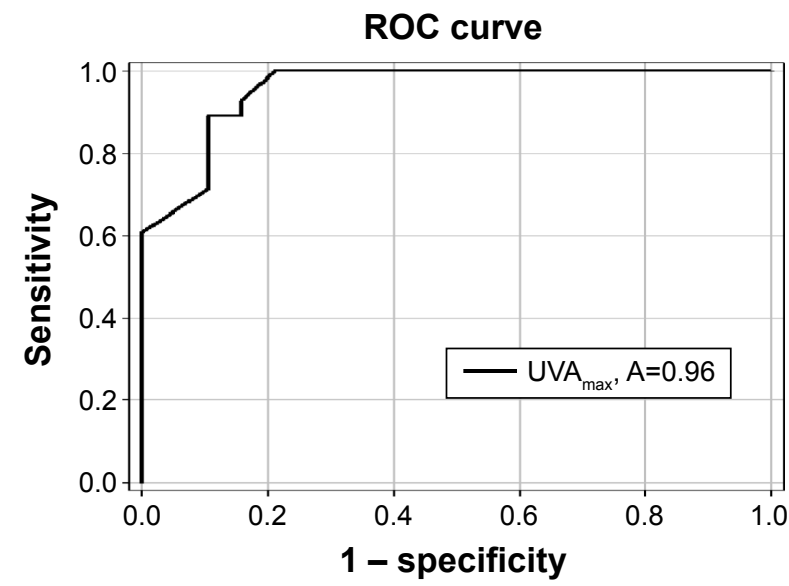

Figure I ROC curve analysis to determinate the sensitivity and specificity of the maximum standardized uptake cutoff value $\left(\mathrm{SUV}_{\max }\right)$ to detect the presence of lymph nodes metastasis.

Abbreviations: ROC, receiver operating characteristic; UVA ${ }_{\max }$, area under the ROC curve.

node metastases significantly reduces survival. ${ }^{1}$ Furthermore, the presence of extracapsular spread in metastatic disease increases the local recurrence rate by 3.5 -fold as compared with oral squamous cell carcinoma without nodal metastasis or metastatic adenopathy without extracapsular spread. ${ }^{2}$

At present, neck dissection with a histological examination is the most reliable means of diagnosing cervical lymph nodes metastasis and extracapsular spread, and it provides important prognostic information. There is a need for a noninvasive procedure that provides prognostic information of the same standard as histopathology.

Nowadays, ${ }^{18}$ F-FDG PET/CT SUV values are being increasingly carried out for staging and localization of

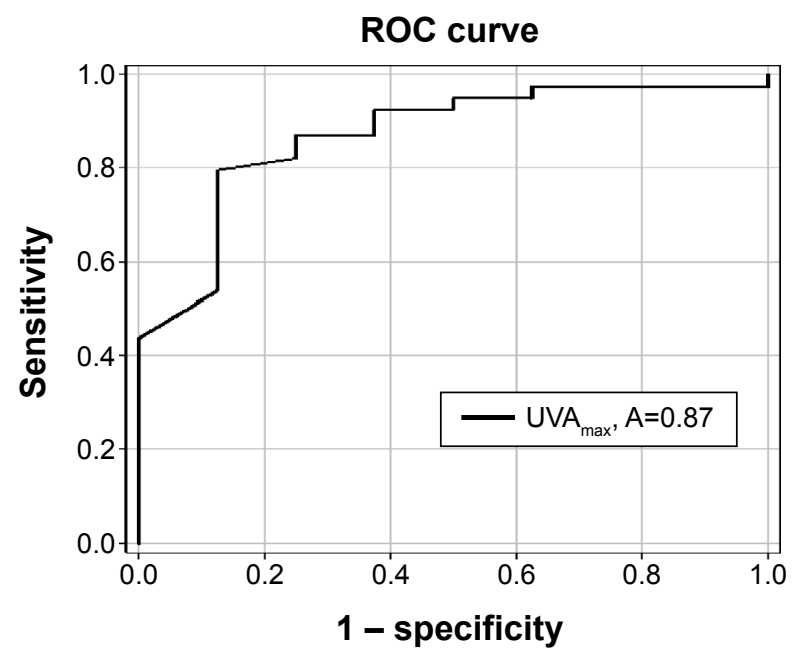

Figure 2 ROC curve analysis to determinate the sensitivity and specificity of the maximum standardized uptake cutoff value $\left(\mathrm{SUV}_{\max }\right)$ to detect the presence of extracapsular spread.

Abbreviations: ROC, receiver operating characteristic; UVA ${ }_{\max }$, area under the ROC curve. 
metastatic disease, and for studying tumor aggressiveness in patients with head and neck cancer. , $^{2,3-9}$

This study was undertaken to assess the value of ${ }^{18} \mathrm{~F}-\mathrm{FDG}$ PET/CT for determining the presence of cervical lymph node metastasis and extracapsular spread in head and neck cancer and to identify its histologic correlates.

In their study, Joo et $\mathrm{al}^{3}$ showed that an optimum FDG

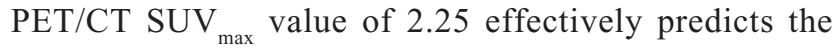
presence of extracapsular spread of cancer from the cervical lymph node with a sensitivity of $85 \%$ and a specificity of $88 \%$.

Furthermore, the study provides evidence that, in addition to lymph node metastasis and extracapsular spread, a median ${ }^{18}$ F-FDG PET/CT SUV ${ }_{\text {max }}$ value of $>3.0$ significantly predicts poor 5-year disease specific survival. In their study, 24 of the 26 patients (92\%) with median ${ }^{18} \mathrm{~F}-\mathrm{FDG}$ PET/CT $\mathrm{SUV}_{\text {max }}$ of $>3.0$ had extracapsular spread.

Consistent with the prior reports, ${ }^{7,8}$ the present results showed that an ${ }^{18}$ F-FDG PET/CT SUV max $_{\text {value of } 4.05}$ was determined to predict the presence of cervical lymph nodes metastases correctly, with a sensitivity of $92 \%$ and a specificity of $88 \%$.

Moreover, an ${ }^{18}$ F-FDG PET/CT SUV max $_{\text {value of } 4.15}$ was found to predict the presence of extracapsular spread of cervical lymph node with a sensitivity of $83 \%$ and a specificity of $88 \%$.

In their study, Kato et $\mathrm{al}^{10}$ demonstrated that the same $\mathrm{SUV}_{\max }$ value with a cutoff of 4.1 was found to be an independent predictive factor, after multivariate analysis, for overall survival.

In their series, Yu et $\mathrm{al}^{11}$ found a lower optimal $\mathrm{SUV}_{\text {max }}$ of 2.36 , at which the sensitivity and specificity was $76 \%$ for detecting lymph node metastases. The area under the ROC curve was 0.9017 .

Lymph node metastases occurred in 21 lymph node groups among the 144 specimens taken from the 16 patients considered. Moreover, data from the literature showed that $\mathrm{SUV}_{\max }$ value could be a significant prognostic factor for overall survival. ${ }^{12,13}$

However, Kim et $\mathrm{al}^{14}$ in their retrospective study that identified 54 patients with surgically resected esophageal cancer who received ${ }^{18} \mathrm{~F}-\mathrm{FDG} \mathrm{PET} / \mathrm{CT}$, did not validate the prognostic value of $\mathrm{SUV}_{\text {max }}$ for regional lymph node metastasis and overall survival.

In conclusion, in our study, a median ${ }^{18} \mathrm{~F}-\mathrm{FDG}$ PET/CT $\mathrm{SUV}_{\max }$ cutoff value of 4.15 was found to be related with cervical lymph node metastasis and extracapsular spread in patients with head and neck cancer, which indicates that $\mathrm{SUV}_{\max }$ could be used as predictor of extracapsular spread, but, at this time and with regard to the literature, $\mathrm{SUV}_{\text {max }}$ value did not provide prognostic information of the same standard as histology.

\section{Disclosure}

The authors report no conflicts of interest in this work.

\section{References}

1. Ng SH, Yen TC, Liao CT, Chang JT, Chan SC, Ko SF. ${ }^{18} \mathrm{~F}-\mathrm{FDG}$ PET and CT/MRI in oral cavity squamous cell carcinoma: a prospective study of 124 patients with histologic correlation. J Nucl Med. 2005; 46:1131-1143.

2. Ng SH, Yen TC, Chang JT, Chan SC, KO SF, Wang HM. Prospective study of (18) fluorodeoxyglucose positron emission tomography and computed tomography and magnetic resonance imaging in oral cavity squamous cell carcinoma with palpably negative neck. J Clin Oncol. 2006;24:4371-4376.

3. Joo YH, Yoo IR, Cho KJ, Park JO, Nam IC, Kim MS. Extracapsular spread and FDG PET/CT correlations in oral squamous cell carcinoma. Int J Oral Maxillofac Surg. 2013;42:158-163.

4. Akoglu E, Dutipek M, Bekis R, Degirmenci B, Ada E, Güneri A. Assessment of cervical lymph node metastasis with different imaging methods in patients with head and neck squamous cell carcinoma. J Otolaryngol. 2005;34:384-394.

5. Schoder H, Carlson DL, Kraus DH, Stambuk HE, Gönen M, Erdi YE. ${ }^{18} \mathrm{~F}$-FDG PET/CT for detecting nodal metastases in patients with oral cancer staged N0 by clinical examination and CT/MRI. J Nucl Med. 2006; 47:755-762.

6. Adam MC, Turkington TG, Wilson JM, Wong TZ. A systematic review of factors affecting accuracy of SUV measurements. AJR Am J Roentgenol. 2010;195:310-320.

7. Greenberg JS, Fowler R, Gomez J, Mo V, Roberts D, El Naggar AK. Extent of extracapsular spread: a critical prognosticator in oral tongue cancer. Cancer. 2003;97:1464-1470.

8. Liao CT, Chang JT, Wang HM, Ng SH, Hsueh C, Lee LY. Pretreatment primary SUVmax measured by FDG-PET and pathologic tumor depth predict poor outcomes in patients with oral cavity squamous cell carcinoma and pathologically positive lymph nodes. Int J Radiat Oncol Biol Phys. 2009;73:764-771.

9. Xie P, Li M, Zhao H, Sun X, Fu Z, Yu J. ${ }^{18}$ F-FDG PET or PET-CT to evaluate prognosis for head and neck cancer: a meta-analysis. J Cancer Res Clin Oncol. 2011;137:1085-1093.

10. Kato H, Nakajima M, Sohda M, et al. The clinical application of (18)F-fluorodeoxyglucose positron emission tomography to predict survival in patients with operable esophageal cancer. Cancer. 2009; 115:3196-3203.

11. Yu W, Fu XL, Zhang YJ, Xiang JQ, Shen L, Chang JY. A prospective evaluation of staging and target volume definition of lymph nodes by 18FDG PET/CT in patients with squamous cell carcinoma of thoracic esophagus. Int J Radiat Oncol Biol Phys. 2011;81:759-765.

12. Choi JY, Jang HJ, Shim YM, et al. ${ }^{18}$ F-FDG PET in patients with esophageal squamous cell carcinoma undergoing curative surgery: prognostic implications. J Nucl Med. 2004;45:1843-1850.

13. Feng R, Li MH, Kong L, Shi F, Yang GR, Yu JM. Correlation between PET-CT 18 FDG uptake in primary lesions and clinicopathological parameters in esophageal carcinoma patients. Zhonghua Zhong Liu Za Zhi. 2009;31(6):452-454.

14. Kim SJ, Kim IJ, Kim K. Predictive value of metabolic tumor volume measured by ${ }^{18} \mathrm{~F}$-FDG PET for regional lymph node status in patients with esophageal cancer. Clin Nucl Med. 2012;37:442-446. 
OncoTargets and Therapy

\section{Publish your work in this journal}

OncoTargets and Therapy is an international, peer-reviewed, open access journal focusing on the pathological basis of all cancers, potential targets for therapy and treatment protocols employed to improve the management of cancer patients. The journal also focuses on the impact of management programs and new therapeutic agents and protocols on

patient perspectives such as quality of life, adherence and satisfaction The manuscript management system is completely online and includes a very quick and fair peer-review system, which is all easy to use. Visit http://www.dovepress.com/testimonials.php to read real quotes from published authors.

Submit your manuscript here: http://www.dovepress.com/oncotargets-and-therapy-journal 